\title{
Robotic and laparoscopic urologic surgery ischemic preconditioning
}

\author{
Murat Zor ${ }^{1}$, Kubra Ozgok Kangal² \\ 'Department of Urology, Gulhane Research and Training Hospital, Ankara 06010, Turkey. \\ 2Department of Undersea and Hyperbaric Medicine, Gulhane Research and Training Hospital, Ankara 06010, Turkey.
}

Correspondence to: Dr. Murat Zor, Department of Urology, Gulhane Research and Training Hospital, Ankara 06010, Turkey. E-mail:murat804@yahoo.com

How to cite this article: Zor M, Kangal KO. Robotic and laparoscopic urologic surgery ischemic preconditioning. Mini-invasive Surg 2018;2:12. http://dx.doi.org/10.20517/2574-1225.2017.34

\author{
Received: 3 Aug 2017 First Decision: 6 Feb 2018 Revised: 24 Feb 2018 Accepted: 8 May 2018 Published: 15 May 2018 \\ Science Editors: Yasar Ozgok, Charles F. Bellows Copy Editor: Jun-Yao Li Production Editor: Cai-Hong Wang
}

\begin{abstract}
Laparoscopic and robotic assisted surgeries have evolved from a limited surgical procedure to a major surgical technique during the last three decades. The indications increased incrementally. Despite its several advantages, it has some surgery and pneumoperitoneum related adverse effects and hemodynamic complications. One of them is the ischemia reperfusion injury (IRI) of the abdominal organs that can be developed secondary to pneumoperitoneum. IRI is also a risk factor for acute kidney injury in partial nephrectomy surgeries even performed via open, or laparoscopic/ robotic assisted. To reduce or avoid the IRI related complications during laparoscopy and robotics, several alternative approaches were suggested including ischemic preconditioning (IPC). IPC is a phenomenon that promotes tissue tolerance to ischemia. Since it was first introduced, several studies evaluating its protective effects or mechanism of action have been published. Majority of them demonstrated its potent beneficial effects against IRI. Despite these favorable results, IPC has not yet been used in clinical settings routinely. The unknown parts of the exact mechanisms, the lack of standard protocols for its use such as the duration of clamping, the number of clamping cycles, using an early window or a late window, using local IP or remote IP, and the all remaining uncertainly about these aspects of the process might lead clinicians to be hesitant about its clinical use. In this study we discussed what we have in our hands regarding the effects of IRI and protective mechanisms of IPC, animal studies and clinical evidence of IPC, remote and local IPC, laparoscopy/robotics induced IRI, and role of laparoscopic/robotic IPC.
\end{abstract}

Keywords: Robotics, laparoscopy, urology, ischemic preconditioning

\section{INTRODUCTION}

Laparoscopic and subsequently developed robotic assisted surgeries have evolved from a limited surgical procedure to a major surgical technique during the last three decades. The indications were increased

\footnotetext{
(). 1

(c) The Author(s) 2018. Open Access This article is licensed under a Creative Commons Attribution 4.0 International License (https://creativecommons.org/licenses/by/4.0/), which permits unrestricted use, sharing, adaptation, distribution and reproduction in any medium or format, for any purpose, even commercially, as long as you give appropriate credit to the original author(s) and the source, provide a link to the Creative Commons license, and indicate if changes were made.
}

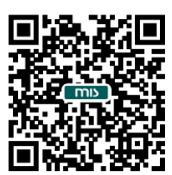


incrementally. Today we can easily say that laparoscopic and robotic surgeries are the most common surgical procedures ${ }^{[1]}$. Despite its several advantages, it has some surgery and pneumoperitoneum related adverse effects and hemodynamic complications.

Ischemia-reperfusion injury (IRI) is a pathological condition characterized by initial undersupply of blood to an area or organ, and subsequent restoration of perfusion and concomitant reoxygenation. Interestingly, this ischemia and reperfusion produce a robust inflammation and oxidative response, and lead to the injury ("reperfusion injury") of microvascular endothelium and renal tubular epithelium ${ }^{[2,3]}$. IRI is a major cause of acute organ dysfunction ${ }^{[4]}$. $\mathrm{CO}_{2}$ pneumoperitoneum is mandatory for visualization during laparoscopic and robotic surgeries. For that reason, it is very logical to infer that creating $\mathrm{CO}_{2}$ pneumoperitoneum may lead tissue/organ ischemia during insufflation and reperfusion during desufflation, a kind of laparoscopy related IRI $^{[5]}$. Schäfer and Krähenbühl ${ }^{[6]}$ demonstrated that pneumoperitoneum leads to a $10 \%-80 \%$ reduction in the rate of blood flow to the intraabdominal organs, but they also reported the return of this reduction to the normal range after desufflation ${ }^{[6]}$. IRI is a risk factor for splanchnic organ injury and liver and kidney are among the intraabdominal organs most severely affected ${ }^{[7]}$. To reduce or avoid the complications related to laparoscopy and robotics, several alternative approaches such as gasless laparoscopy, lower pressure laparoscopy and ischemic preconditioning (IPC) are introduced. IRI is also a risk factor for acute kidney injury in partial nephrectomy surgeries even performed via open, or laparoscopic/robotic assisted. We know that partial nephrectomy is the treatment of choice for small, localized renal tumors ${ }^{[8]}$, and it is generally performed with occlusion of kidney vascular supply, leading to IRI. To reduce this kind of injury, several methods are proposed and investigated in the literature such as early hilar unclamping ${ }^{[9]}$, renal hypothermia ${ }^{[10]}$, segmental renal artery clamping ${ }^{[11]}$, and selective branch microdissection ${ }^{[12]}$ (beyond the scope of this review), and IPC ${ }^{[13]}$.

IPC is a phenomenon. It was first introduced in 1986 by Murry et al. ${ }^{[1]}$. In their study on dogs, they were able to show reduced myocardial infarct size by IPC ${ }^{[1]}$. Since then, in contrast to some small studies with conflicting results, several studies demonstrating its protective effects on kidney have been published.

This article will provide an updated summary of the effects of IRI and protective mechanisms of IPC. We will also discuss the animal studies and clinical evidence of IPC, remote and local IPC, laparoscopy/robotics induced IRI. The last section will review the main topic, role of laparoscopic/robotic IPC. For this purpose, an extensive search of literature in PubMed was performed. "Ischemia reperfusion injury" and "ischemic preconditioning" key words were used. It was not restricted to any year but language was restricted to English. All relevant studies to make an update on the topic were reviewed.

\section{IRI AND PROTECTIVE MECHANISMS OF IPC}

The inflammatory cascade that is triggered by ischemia and subsequent reperfusion plays the major role in IRI. In their study Fan et al. ${ }^{[15]}$ have demonstrated that leukocyte activation, invasion, adhesion, and impaction evidently occur in ischemic reperfusion kidney injury. This leads release of several substances and mediators such as free radicals, lysosomal enzymes and various cytokines causing cell damage, which is called IRI ${ }^{[16]}$. To overcome this tissue injury many studies suggested the IPC. Underlying mechanisms of action of the protective effect of this procedure have been studied in several trials. In their study MahfoudhBoussaid et al ${ }^{[17]}$ found that IPC reduced lipid peroxidation and showed elevated levels of endothelial nitric oxide synthase, nitrite and hypoxia inducible transcription factor- $1 \alpha$. Kim et al ${ }^{[18]}$ suggested the protective effect of isositrate dehydrogenase in IPC. Chen et al. ${ }^{[19]}$ proposed the NF-kappa B as the key mediator for reperfusion injury and showed that IPC significantly reduced the expressions of renal adhesion molecules ICAM-1, P-selectin, and E-selectin. Fan et al. ${ }^{[15]}$ also believed that the reduction of adhesion molecules is an important step in preventing IRI. Many other studies confirmed that the adhesion molecules have 
paramount importance in IRI ${ }^{[20,21]}$. In their study, Xue et al. ${ }^{[22]}$ demonstrated the evidence that IPC mediated homing of endothelial progenitor cells played an important role in the protection of IRI. Despite all these increasing number of published studies evaluating the exact mechanisms of IRI, protective effects of IPC remains far from complete.

\section{ANIMAL STUDIES AND CLINICAL EVIDENCE OF IPC}

Since Murry et al. ${ }^{[1]}$ described IPC in the late 1980s, several studies demonstrating its protective effects on kidney have been published. In 2012, Wever et al. ${ }^{[16]}$ published a systematic review and meta-analysis of experimental animal studies regarding renal IPC. Serum creatinine, BUN levels and histologic changes were evaluated. They found that serum creatinine and BUN levels decreased significantly and the histologic changes were less important in the IPC group. They also performed subgroup analysis to investigate several predefined factors such as window of protection (early or late), site of preconditioning (remote and local), species (mouse or rat) and gender. In conclusion they found that IPC had persistent protective effects in all subgroups except for female experiments (only two studies). This meta-analysis indisputably demonstrates that renal IPC has protective effects to subsequent IRI, at least for small animals, since $91 \%$ of all studies were performed in rats or mice. On the flip side, there are unfortunately limited numbers of larger animal studies, with conflicting results. In a porcine model, Hernandez et al. ${ }^{[23]}$ demonstrated that IPC had no protective effect. Yoon et al. ${ }^{[24]}$ also demonstrated similar results. In their study on pigs, they found that IPC had no effect on serum creatinine. In contrast, levels of renal injury markers were lower in the late phase of IPC performed pigs, indicating protective effect that was not reflected in serum creatinine. Taken together, later studies suggest that the positive protective effects of IPC in small animals like rats may not be applicable to larger animal models. It seems that alternative IPC regimens need to be determined in the future.

In the light of the studies published to date, now we can talk about that IPC induces biphasic protection against IRI. Early mediators including adenosine, bradykinins, catecholamines, and opioids provide a strong, but short-lived, "classic" early protection ${ }^{[25,26]}$. While short-term mediators provide the initial protection, the activation of transcription factors and de novo protein synthesis provide a late onset, less stronger but more durable protection against ischemia called "second window of protection" ${ }^{\text {"[2] }}$. The concept was previously described for cardiac IPC but it is also applicable for renal IPC ${ }^{[28]}$. In a systematic review, Wever et al. ${ }^{[16]}$ demonstrated that second window ( $\geq 24 \mathrm{~h}$ ) of protection was more effective in decreasing serum creatinine after renal IRI. In their study on dogs, Kosieradzki et al. ${ }^{[29]}$ were not able to demonstrate either early or late protective effects of IPC. But the study was performed on dogs and previous studies demonstrated that the effect of IPC in each animal species varies.

\section{REMOTE ISCHEMIC PRECONDITIONING}

In routine clinical practice the role of local IPC is very limited due to the increased risk of damage to the vascular structures. Additionally, even short-term ischemia may lead further injury in the target tissue. To avoid from the effects of local IPC the term of remote IPC is introduced, which is a more potentially clinically practical technique. This term describes the application of IPC stimulus to a remote organ e.g. a limb, which is relatively resistant to IRI. The underlying mechanisms of remote IPC are not fully demonstrated, but current concepts suggest that the protective mediators are produced secondary to the stimulus created by remote IPC. These produced mediators carry the protective effect from the site of remote IPC to the target organ ${ }^{[30]}$. It can be performed noninvasively by simply inflating and deflating a standard blood-pressure cuff placed on the upper arm or thigh to induce transient ischemia and reperfusion ${ }^{[31]}$. Most of the studies published to date demonstrated its cardiac protective effects, but there are also some studies that have revealed the potential of protective properties on kidney injury. Wever et al. ${ }^{[16]}$ reported $30 \%$ to $60 \%$ improvement of renal protection and reduction of renal tubule damage with remote IPC. In another study, Ali et al. ${ }^{[32]}$ found that it reduced the incidence of renal impairment. In the meta-analysis of Wever et al. ${ }^{[16]}$, renoprotective effects of brief 
hind limb occlusion were reported in rats. They suggested that remote IPC has an at least equal potential for translation to clinic. In contrast with these studies, Bedir et al.$^{[33]}$ conducted a study on a porcine model, and they compared serum creatinine levels and histopathological changes. But they were unable to demonstrate any significant difference on behalf of IPC. Although large animal studies were not able to demonstrate any protective effect of both remote and local IPC against IRI, this should be interpreted cautiously before giving up this technique totally. Huang et al. ${ }^{[13]}$ recently published a randomized, controlled study in humans, which was evaluating the effects of remote IPC. They demonstrated that lower limb IPC might reduce renal damage in patients undergoing laparoscopic partial nephrectomy.

In conclusion we can say that the positive protective effects of remote IPC on kidney injury against ischemia is limited, and its advantages are still questionable. Similar with local applications, remote IPC studies conducted in small animals have yielded encouraging results, but their applicability to humans needs further research. Unfortunately larger animal and human studies are very limited, and they have conflicting results.

\section{IRI SECONDARY TO LAPAROSCOPIC/ROBOTIC PNEUMOPERITONEUM}

Laparoscopic surgery requires adequate pneumoperitoneum throughout the surgery, but it has some well-known physiologic adverse effects on cardiac ${ }^{[34]}$, pulmonary ${ }^{[35]}$, and renal systems ${ }^{[36]}$. The decreased blood flow to visceral organs and increased systemic vascular resistance, which are developed secondary to increased intra-abdominal pressure are mainly responsible for these adverse effects. Additionally, the subsequent desufflation following pneumoperitoneum may lead to an IRI. Eleftheriadis et al. ${ }^{[36]}$ were firstly able to demonstrate the increased oxidative stress in the rat liver after pneumoperitoneum. In their study, Glantzounis et al.$^{[37]}$ reported increased levels of free oxygen radicals after laparoscopic procedures, which were probably developed secondary to IRI. Akbulut et al. ${ }^{[38]}$ firstly demonstrated the pneumoperitoneum related increased oxidative stress in kidneys.

To date lower pressure model ${ }^{[39,40]}$, low-pressure pneumoperitoneum with intermittent deflation at distinct time point ${ }^{[41]}$ and IPC have been attempted to reduce ischemic injury regarding pneumoperitoneum. Many human and animal studies have investigated the effects of increasing intraabdominal pressures (IAP) during laparoscopy and the benefits of low IAP. In different studies Giraudo et al. ${ }^{[39]}$ and Samel et al. ${ }^{[40]}$ obviously revealed that lower IAPs were related with reduced oxidative injury. But there are also some contradictory studies. In their study on rats, Yilmaz et al.$^{[42]}$ did not demonstrate any statistical significance in oxidative stress parameters at both low and high intraabdominal pressures. Polat et al ${ }^{[43]}$ confirmed these results in their study with human subjects. A recent study conducted by Biler et al ${ }^{[44]}$ clearly demonstrated that the ischemic preconditioning method should be used to reduce IRIs, rather than other low-pressure models.

\section{ROLE OF LAPAROSCOPIC/ROBOTIC IPC}

Since Murry et al. ${ }^{[1]}$ first described the IPC, it was adopted for different laparoscopic studies. It has been proposed as an effective therapeutic approach to enhance ischemia tolerance and preserve intraabdominal organ function ${ }^{[3,45]}$. Yilmaz et al. ${ }^{[46]}$ first demonstrated that laparoscopic preconditioning might decrease the oxidative stress in intestines following laparoscopic procedures in rats. In another study of the same group, Yilmaz et al. ${ }^{[4]]}$ demonstrated that LPC consisting of $10 \mathrm{~min}$ of insufflation followed by $10 \mathrm{~min}$ of desufflation reduced the oxidative stress that induced by long-term increased intraabdominal pressure in the plasma, liver, and kidney. But they also concluded that further studies were warranted to determine its ideal timing, before incorporating LPC to clinical applications, because the experimental protocol was too long to be applicable for the usage in humans. In the literature, different time periods for preconditioning method have been reported. However, 5- or 10-min-ischemia followed by a reperfusion of 5-10 min is used most commonly ${ }^{[1,48]}$. Arioz et al. ${ }^{[49]}$ published a study in 2009, and compared LPC 5-min with LPC 10-min. As a result, they concluded that $5 \mathrm{~min}$ of pneumoperitoneum, and subsequent $5 \mathrm{~min}$ of desufflation, seems 
to be comparable to $10 \mathrm{~min}$ of inflation and desufflation periods, against laparoscopic IRI. So they suggested it to be more practical for clinical use ${ }^{[49]}$. It is important to mention that to date there is no human studies to assess the role of described laparoscopic/robotic IPC.

\section{CONCLUSION}

The potential positive effects of IPC against IRI have been demonstrated by several studies over the past 2 decades. Despite these encouraging findings, IPC has not been routinely used in clinical settings yet. One of the major reasons of this situation is the very limited number of larger animal and human studies and regarding conflicting results. The unknown parts of the exact mechanisms, the lack of standard protocols for its use such as clamping time, number of clamping cycles for remote IPC, using an early window or a late window, using local IPC or remote IPC, and the all remaining uncertainty regarding this process might lead clinicians to be hesitant about its clinical use. In their study in 2000, Yellon and Dana ${ }^{[50]}$ asked the question: “The preconditioning phenomenon: a tool for the scientist or a clinical reality?" It is nearly passed two decades, but the same question hasn't lost its currency yet. We also agree with them and many others who made great effort on this topic that more work is needed on IRI, IPC and LPC before its adaptation to clinical settings to become something more than a tool for the scientist.

\section{DECLARATIONS}

\section{Authors' contributions}

Substantial contribution to conception and design, and acquisition of data, and analysis and interpretation of data: Zor M

Drafting the article and revising it critically for important intellectual content: Kangal KO

Giving the final approval of the version to be submitted and any revised version: Zor M

\section{Financial support and sponsorship}

None.

\section{Conflicts of interest}

All authors declared that there are no conflicts of interest.

\section{Patient consent}

Not applicable.

\section{Ethics approval}

Not applicable.

\section{Copyright}

(c) The Author(s) 2018.

\section{REFERENCES}

1. Murry CE, Jenning RB, Reimer KA. Preconditioning with ischaemia: a delay of lethal cell injury in ischemic myocardium. Circulation 1986;74:1124-36.

2. Bonventre JV, Yang L. Cellular pathophysiology of ischemic acute kidney injury. J Clin Invest 2011;121:4210-21.

3. Eltzschig HK, Eckle T. Ischemia and reperfusion from mechanism to translation. Nat Med 2011;17:1391-401.

4. Ii M, Nishimura H, Iwakura A, Wecker A, Eaton E, Asahara T, Losordo DW. Endothelial progenitor cells are rapidly recruited to myocardium and mediate protective effect of ischemic preconditioning via "imported" nitric oxide synthase activity. Circulation 2005;111:1114-20.

5. O’Malley C, Cunningham AJ. Physiologic changes during laparoscopy. Anesthesiol Clin North Am 2001;19:1-19.

6. Schäfer M, Krähenbühl L. Effects of laparoscopy on intra-abdominal blood flow. Surgery 2001;129:385-9. 
7. Schachtrupp A, Toens Ch, Hoer J, Klosterhalfen B, Lawong AG, Schumpelick V. A 24-h pneumoperitoneum leads to multiple organ impairment in a porcine model. J Surg Res 2002;106:37-45.

8. Campbell SC, Novick AC, Belldegrun A, Blute ML, Chow GK, Derweesh IH, Faraday MM, Kaouk JH, Leveillee RJ, Matin SF, Russo P, Uzzo RG; Practice Guidelines Committee of the American Urological Association. Guideline for management of the clinical T1 renal mass. J Urol 2009;182:1271-9.

9. Petrasz P, Slojewski M, Sikorski A. Impact of "nonclamping technique" on intra- and postoperative course after laparoscopic partial nephrectomy. Wideochir Inne Tech Maloinwazyjne 2012;7:275-9.

10. Abe T, Sazawa A, Harabayashi T, Shinohara N, Maruyama S, Morita K, Matsumoto R, Aoyagi T, Nonomura K. Renal hypothermia with ice slush in laparoscopic partial nephrectomy: the outcome of renal function. J Endourol 2012;26:1483-8.

11. Shao P, Qin C, Yin C, Meng X, Ju X, Li J, Lv Q, Zhang W, Xu Z. Laparoscopic partial nephrectomy with segmental renal artery clamping: technique and clinical outcomes. Eur Urol 2011;59:849-55.

12. Gill IS, Eisenberg MS, Aron M, Berger A, Ukimura O, Patil MB, Campese V, Thangathurai D, Desai MM. "Zero ischemia" partial nephrectomy: novel laparoscopic and robotic technique. Eur Urol 2011;59:128-34.

13. Huang J, Chen Y, Dong B, Kong W, Zhang J, Xue W, Liu D, Huang Y. Effect of remote ischaemic preconditioning on renal protection in patients undergoing laparoscopic partial nephrectomy: a 'blinded' randomised controlled trial. BJU Int 2013;112:74-80.

14. Zhao ZQ, Corvera JS, Halkos ME, Kerendi F, Wang NP, Guyton RA, Vinten-Johansen J. Inhibition of myocardial injury by ischemic postconditioning during reperfusion: Comparison with ischemic preconditioning. Am J Physiol Heart Circ Physiol 2003;285:H579-88.

15. Fan LH, He L, Cao ZQ, Xiang B, Liu L. Effect of ischemia preconditioning on renal ischemia/reperfusion injury in rats. Int Braz J Urol 2012;38:842-54

16. Wever KE, Menting TP, Rovers M, van der Vliet JA, Rongen GA, Masereeuw R, Ritskes-Hoitinga M, Hooijmans CR, Warlé M. Ischemic preconditioning in the animal kidney, a systematic review and meta-analysis. PLoS One 2012;7:e32296.

17. Mahfoudh-Boussaid A, Zaouali MA, Hadj-Ayed K, Miled AH, Saidane-Mosbahi D, Rosello-Catafau J, Ben Abdennebi H. Ischemic preconditioning reduces endoplasmic reticulum stress and upregulates hypoxia inducible factor-1 $\alpha$ in ischemic kidney: the role of nitric oxide. J Biomed Sci 2012;19:7.

18. Kim J, Kim JI, Jang HS, Park JW, Park KM. Protective role of cytosolic NADP(+)-dependent isocitrate dehydrogenase, IDH1, in ischemic pre-conditioned kidney in mice. Free Radic Res 2011;45:759-66.

19. Chen X, Liu X, Wan X, Wu Y, Chen Y, Cao C. Ischemic preconditioning attenuates renal schemia-reperfusion injury by inhibiting activation of IKKbeta and infl ammatory response. Am J Nephrol 2009;30:287-94.

20. Koo DD, Welsh KI, West NE, Channon KM, Penington AJ, Roake JA, Morris PJ, Fuggle SV. Endothelial cell protection against ischemia/reperfusion injury by lecithinized superoxide dismutase. Kidney Int 2001;60:786-96.

21. Singbartl K, Ley K. Protection from ischemia-reperfusion induced severe acute renal failure by blocking E-selectin. Crit Care Med 2000;28:2507-14.

22. Xue J, Qin Z, Li X, Cao P, Jia R. Protective effects of ischemic preconditioning-mediated homing of endothelial progenitor cells on renal acute ischemia and reperfusion injury in male rats. Ann Transplant 2017;22:66-74.

23. Hernandez DJ, Roberts WB, Miles-Thomas J, Magheli A, Saha S, Schaeffer EM, Racusen LC, Allaf ME. Can ischemic preconditioning ameliorate renal ischemia-reperfusion injury in a single-kidney porcine model? J Endourol 2008;22:2531-6.

24. Yoon YE, Lee KS, Choi KH, Kim KH, Yang SC, Han WK. Preconditioning strategies for kidney ischemia reperfusion injury: implications of the "time-window" in remote ischemic preconditioning. PLoS One 2015; 10:e124130.

25. Ambros JT, Herrero-Fresneda I, Borau OG, Boira JM. Ischemic preconditioning in solid organ transplantation: from experimental to clinics. Transpl Int 2007;20:219-29.

26. Pasupathy S, Homer-Vanniasinkam S. Ischaemic preconditioning protects against ischaemia/reperfusion injury: emerging concepts. Eur J Vasc Endovasc Surg 2005;29:106-15.

27. Orvieto MA, Zorn KC, Mendiola FP, Gong EM, Lucioni A, Mikhail AA, Gofrit ON, Shalhav AL. Ischemia preconditioning does not confer resilience to warm ischemia in a solitary porcine kidney model. Urology 2007;69:984-7.

28. Yamashita N, Hoshida S, Taniguchi N, Kuzuya T, Hori M. A "second window of protection" occurs $24 \mathrm{~h}$ after ischemic preconditioning in the rat heart. J Mol Cell Cardiol 1998;30:1181-9.

29. Kosieradzki M, Ametani M, Southard JH, Mangino MJ. Is ischemic preconditioning of the kidney clinically relevant? Surgery 2003;133:81-90.

30. Heusch G, Bøtker HE, Przyklenk K, Redington A, Yellon D. Remote ischemic conditioning. J Am Coll Cardiol 2015;65:177-95.

31. Kharbanda RK, Mortensen UM, White PA, Kristiansen SB, Schmidt MR, Hoschtitzky JA, Vogel M, Sorensen K, Redington AN, MacAllister R. Transient limb ischemia induces remote ischemic preconditioning in vivo. Circulation 2002;106:2881-3.

32. Ali ZA, Callaghan CJ, Lim E, Ali AA, Nouraei SA, Akthar AM, Boyle JR, Varty K, Kharbanda RK, Dutka DP, Gaunt ME. Remote ischemic preconditioning reduces myocardial and renal injury after elective abdominal aortic aneurysm repair: a randomized controlled trial. Circulation 2007;116:198-105.

33. Bedir S, Ma Y, Antonelli J, Cadeddu JA, Gahan JC. Ineffectiveness of remote ischemic renal preconditioning in a porcine solitarykidney model. J Endourol 2015;29:590-4.

34. Galizia G, Prizio G, Lieto E, Castellano P, Pelosio L, Imperatore V, Ferrara A, Pignatelli C. Hemodynamic and pulmonary changes during open, carbon dioxide pneumoperitoneum, and abdominal wall-lifting cholecystectomy. A prospective, randomized study. Surg Endosc 2001;15:477-83.

35. Wittgen CM, Andrus CH, Fitzgerald SD, Baudendistel LJ, Dahms TE, Kaminski DL. Analysis of the hemodynamic and ventilatory effects of laparoscopic cholecystectomy. Arch Surg 1991;126:997-1000. 
36. Eleftheriadis E, Kotzampassi K, Papanotas K, Heliadis N, Sarris K. Gut ischaemia, oxidative stress, and bacterial translocation in elevated abdominal pressure in rats. World J Surg 1996;20:11-6.

37. Glantzounis GK, Tselepis AD, Tambaki AP, Trikalinos TA, Manataki AD, Galaris DA, Tsimoyiannis EC, Kappas AM. Laparoscopic surgery-induced changes in oxidative stress markers in human plasma. Surg Endosc 2001;15:1315-9.

38. Akbulut G, Serteser M, Polat C, Köken T, Aktepe F, Yilmaz S, Gokçe C, Gökçe O. Changes in tissue oxidative stress markers in an experimental model of laparoscopic donor nephrectomy. Transplantation 2002;74:1768-72.

39. Giraudo G, Brachet Contul R, Caccetta M, Morino M. Gasless laparoscopy could avoid alterations in hepatic function. Surg Endosc 2001;15:741-6.

40. Samel ST, Neufang T, Mueller A, Leister I, Becker H, Post S. A new abdominal cavity chamber to study the impact of increased intraabdominal pressure on microcirculation of gut mucosa by using video microscopy in rats. Crit Care Med 2002;30:1854-8.

41. Richter S, Olinger A, Hildebrandt U, Menger MD, Vollmar B. Loss of physiologic hepatic blood flow ("hepatic arterial buffer response") during CO2-pneumoperitoneum in the rat. Anesth Analg 2001;93:872-7.

42. Yilmaz S, Polat C, Kahraman A, Koken T, Arikan Y, Dilek ON, Gîkáe O. The comparison of the oxidative stress effects of different gases and intra-abdominal pressures in an experimental rat model. J Laparoendosc Adv Surg Tech A 2004;14:165-8.

43. Polat C, Yilmaz S, Serteser M, Koken T, Kahraman A, Dilek ON. The effect of different intra-abdominal pressures on lipid peroxidation and protein oxidation status during laparoscopic cholecystectomy. Surg Endosc 2003;17:1719-22.

44. Biler A, Yucebilgin S, Sendag F, Akman L, Akdemir A, Ates U, Uyanikgil Y, Yilmaz-Dilsiz O, Sezer E. The effects of different intraabdominal pressure protocols in laparoscopic procedures on oxidative stress markers and morphology in rat ovaries. Adv Clin Exp Med 2014;23:885-92.

45. McCafferty K, Byrne C, Yaqoob MM. Ischaemic conditioning strategies for the nephrologist: a promise lost in translation? Nephrol Dial Transplant 2014;29:1827-40.

46. Yilmaz S, Ates E, Polat C, Koken T, Tokyol C, Akbulut G, Gokce O. Ischaemic preconditioning decreases laparoscopyinduced oxidative stress in small intestine. Hepatogastroenterology 2003;50:979-82.

47. Yilmaz S, Koken T, Tokyol C, Kahraman A, Akbulut G, Serteser M, Polat C, Gokce C, Gokce O. Can preconditioning reduce laparoscopy-induced tissue injury? Surg Endosc 2003;17:819-24.

48. Imamoglu M, Cay A, Unsal MA. The effects of increased intraabdominal pressure on testicular blood flow, oxidative stres markers, and morphology. J Pediatr Surg 2006;41:1118-24.

49. Arioz DT, Polat C, Tokyol C, Kakraman A, Yilmaz S, Demirel R, Saylan A, Yilmazer M, Tekin A. What should be the ideal time for ischemic preconditioning in a laparoscopic rat model? J Laparoendosc Adv Surg Tech A 2009;19:141-7.

50. Yellon DM, Dana A. The preconditioning phenomenon: a tool for the scientist or a clinical reality? Circ Res 2000;87:543-50. 